\title{
From Teaching Assistant (TA) Training to Workplace Learning
}

Cynthia Korpan, University of Victoria

\begin{abstract}
In this paper, I propose a renewed look at how teaching assistants (TAs) are being prepared to fulfill their duties in higher education. I argue that the apprenticeship model of learning that is currently in use be replaced by the more holistic workplace learning approach. Workplace learning theories take into consideration the complexity of the learning situation of the TA.
\end{abstract}

The teaching assistant came into my office to talk about the work that she had been assigned. Quite distraught, she relayed how she knew nothing about the course content and did her best to

follow the guidelines provided by the course supervisor. Despite seeking teaching support, students in the TA's lab soon began to lack confidence in her as their teacher. In turn, her confidence was shattered and her ability to perform as a TA quickly diminished.

It is often the case that when I walk across campus, faculty will stop me to tell me his or her story about working with teaching assistants. One day, a professor told me the story about how

she had found out, due to poorly graded assignments that the TA, instead of grading the assignments herself, had delegated this to her husband, who was not affiliated with the discipline or university.

In my role as the TA Training Program Manager at the University of Victoria (UVic), I hear many stories about TAs. No matter if the story comes from a teaching assistant (TA) or faculty member, both are seeking the same end result - that TAs do their job well. Too often a TA feels he or she is not able to fulfill his or her duties sufficiently because of a lack of skills and required knowledge, which leads to a lack of confidence and employing inappropriate methods of approaching his or her work.

My colleagues and I at institutions across North America devise programs and courses that address issues pertaining to TAs' lack of skills and confidence. I began working in the field of teaching assistant training and graduate student professional development in 2006. At that time, one of the main foci was on programs that prepared graduate students to be faculty members. This focus was influenced by the introduction in the early 2000s of a heavily-funded program in the United States (US), called Preparing Future Faculty (PFF) that favours professional development of future faculty. Despite similar programs already existing, the development of this program helped spawn PFF-type programs at most higher education institutions in North America. UVic, as with many Canadian post-secondary institutions, had such a program put in place in the mid-2000s. The program at UVic changed in 2012 (approved by Senate in January with first intake of students in September, 2012) to become Learning and Teaching in Higher Education (LATHE), a six-unit (two 1.5 credit courses, and one 3.0 credit course) graduate certificate program that is listed on the student's transcript (not just a notation 
in the comments section). It is jointly offered by the Learning and Teaching Centre, Educational Psychology and Leadership Studies, and the Faculty of Graduate Studies.

Certificate programs that prepare future faculty are important but I contend that the focus on preparing to teach in higher education should be at the beginning, when a graduate student first steps into an instructional position in post-secondary education. The recent quality movement in higher education brings attention to how undergraduate students are being supported, especially in the first and second years of their degree. If the underlying movement is to make sure we are providing the best quality undergraduate education, then we need to focus closely on the teaching assistant role. Approximately one-third of first- and second-year courses at UVic (similar percentages must exist at other institutions) have a tutorial, discussion, or lab component that have TAs as the lead instructor.

\section{Teaching assistant}

In a significant number of higher education institutions in Canada, graduate students are given the opportunity to assist a professor with instructional duties that begins their learning process about the culture of teaching at a university with its norms and responsibilities. Sometimes undergraduate students take on the role of a TA, but the focus here is strictly on graduate students. How a TA learns the duties, norms, and responsibilities of his or her work assignment is dependent on the course supervisor or other department designate. This model of learning, where a graduate student assists a professor, is termed an apprenticeship model.

In my work, I question whether the apprenticeship model is the best method of learning for the TA role in Canadian universities. From my perspective, the TA role has been conflated with the graduate student role. I propose another model of learning, called workplace learning. Workplace learning has similar features as the apprenticeship model but provides a more holistic approach to work and learning. I will first discuss the apprenticeship model, its historical roots in higher education, and recent remodeling for graduate education. I will then discuss workplace learning, and how it suits the TA role as a pedagogical method of learning.

\section{The apprenticeship model}

Apprenticeship is a means of imparting specialized knowledge to a new generation of practitioners by modeling a way of being (Walker, Golde, Jones, Bueschel, \& Hutchings, 2008). It is a reproductive model (Walker, Golde, Jones, Bueschel, \& Hutchings, 2008) that transforms novices into experts. Apprenticeship is typically employed where there is primarily implicit knowledge to be acquired through long-term observation and experience.

Before the industrial revolution, apprenticeship was a common learning process used throughout the world (Aldrich, 1991). Even though the traditional historical forms of apprenticeship diminished in the Western world at that time, the model survived and is actively used as the best method to teach many different skills and for the transmission of knowledge (for examples consult Ainley \& Rainbird, 1991; Lave, 1988; and Lave \& Wenger, 1991). It is also the pedagogical method preferred in practices that deal with a lot of complexity, multiple procedures, and dynamic environments, such as in medicine, police work, and professional development (Johnson \& Pratt, 1998). Many of the principles and practices of apprenticeship, sometimes referred to as internship, were applied to the university in professional areas such as medicine and law, which continue to this day (Aldrich, 1991). Additionally in the university, it took the form of the faculty "master" and the graduate student "apprentice." TAs, as graduate students, were positioned similarly, as apprentices but termed assistants. 
Apprenticeship, as a process of learning, has received significant attention in recent years. Jean Lave based on her fieldwork studying apprenticeships of Vai and Gola tailors of Liberia, with Etienne Wenger (1991) took a renewed look at the social practice of apprenticeship to suggest that it be re-envisioned as situated learning, emphasizing that learning is not an individual cognitive process but rather an encompassing social practice.

Moreover, Lave and Wenger (1991) identify that the social practice of apprenticeship is part of a community of practice $(\mathrm{CoP})$. A $\mathrm{CoP}$ is considered to be any activity that is shared by a group of people through a series of social relations, either work- or socially-based that occur over time to support collective learning of a common practice or profession (Wenger, 1988). One characteristic often associated with apprenticeship is that novices eventually replace experts. However, Lave and Wenger refute the expert/novice relationship historically related to apprenticeship, favouring a relationship that benefits the whole community as everyone is gaining knowledge through the interactions taking place.

To describe the apprentice's role, Lave and Wenger (1991) coined the phrase, legitimate peripheral participation. They argue that the term defines how a newcomer is in a peripheral position because he or she is just beginning to learn the language and social rules associated with the roles in the community; legitimate because everyone recognizes the newcomer as part of the community; and lastly, that he or she will participate in ways determined by the community to be the best to ensure that he or she learns to do the activity correctly and appropriately. Legitimate peripheral participant is another way to describe the positioning of an apprentice or assistant in a learning and work situation.

\section{Signature Pedagogies}

Following Lave and Wenger's (1991) re-envisioning of apprenticeship, the apprenticeship model used in higher education to prepare graduate students has come under scrutiny. The Carnegie Foundation for the Advancement of Teaching, a research and policy centre focused on improving teaching and learning in the US, recently conducted a five-year study of graduate education. The research was about the whole graduate experience, including teaching activities, and confirmed that the apprenticeship model is the signature pedagogy of graduate education (Walker, Golde, Jones, Bueschel, \& Hutchings, 2008). The term "signature pedagogies" comes from Lee S. Shulman (2005) and is described as the "characteristic forms of teaching and learning...that organize the fundamental ways in which future practitioners are educated for their new professions" (p. 52). Signature pedagogies are windows into the cultures of their fields because they incorporate into the acts of teaching and learning, assumptions about how to teach knowledge and skills, such as how to think like a lawyer. The Carnegie Foundation took a hard look at the apprenticeship model used with graduate students and found that when apprenticeship works well, it can be an incredibly powerful experience, but withstanding that, they question whether it is the best model to use, and if not, what would be better.

\section{TAs as apprentices}

Today, at most Canadian universities, a significant number of the graduate student population are TAs during any term (at UVic about one third for both the fall and winter terms). The duties assigned to a TA differ from department to department, institution to institution, but run the full gamut associated with a teaching position in higher education.

TA teaching has been the subject of a wide range of publications and research (for e.g., Austin, 2002a; Austin, 2002b; Bellows, 2008; Boman, 2008; Cho, Kim, Svinicki, \& Decker, 
2011; Garland, 1983; Jones, 1993; Lumsden, Grosslight, Loveland, \& Williams, 1988; Marincovich, Prostko, \& Stout, 1998; Nyquist, Manning, Wulff, Austin, Sprague, Fraser, Calcagno, \& Woodford 1999; Schonwetter, Ellis, Nazarko, \& Taylor 2004; Weber, Gabbert, Kropp, \& Pynes, 2007). The bulk of the information identifies topics that TAs should be exposed to, such as basic teaching preparation for higher education classrooms and suggestions on how to familiarize TAs with this content through workshops and programs. To provide this information to TAs, departments and learning and teaching centres develop training opportunities, materials, and programs. How each course supervisor prepares TAs assigned, varies greatly.

No matter how much is in place to help prepare TAs for teaching, many take up their TA role with little or no preparation. For example, a survey conducted at UVic in 2009 revealed that $65 \%$ of new TAs had not engaged in or been exposed to any teaching preparation before beginning their duties (Korpan, 2010). This means that most faculty, departments, and TAs rely on apprenticeship as the dominant learning process in order to learn how to fulfill their duties.

\section{Problems with the Apprenticeship Model for TAs}

There is the assumption that TA work prepares a graduate student for future academic work. But, as a reproductive model, it continually reproduces TAs not colleagues (Long, Holberg, \& Taylor, 1996). The range of complexity that is involved in being an instructor in higher education is obscured. The work experience of TAs is fragmented and does not represent the complexity of being the professor for a complete course. Therefore, a professor does not provide the best mentor for TAs in an apprenticeship model; actually, an experienced TA provides the best mentorship for TA work.

Typically, one professor is responsible for preparing a student to be a TA (Long, Holberg, \& Taylor, 1996), which besides being a time consuming task for the professor, gives only one perspective on how to approach particular issues that surface during the term of an assignment.

Further, there is a rigid differential in status and power between a professor and TA (Long, Holberg, \& Taylor, 1996): the TA is bound to work and learn from the professor but limited in his or her ability to suggest different approaches to the work assigned.

Also, the learning taking place is often uni-directional, determined solely by the professor (Long, Holberg, \& Taylor, 1996). While the TA does learn through practical experience, he or she is "under" professors who are skilled, the TA him- or herself being a "novice." In terms of teaching, if a TA gets the chance to guest lecture, the TA is entering someone else's classroom for a short time but is always under the direction of the professor (Long, Holberg, \& Taylor 1996).

Additionally, most training provided for TAs is primarily focused on skill- and rule-based actions (Ainley \& Rainbird, 1991; Coy, 1989; Lave \& Wenger, 1991). Skill-based actions do not require a lot of subjective attention and are learned in order to maintain the norm of that skill. Rule-based actions are based on rules or procedures that can be easily adapted and revised as needed but only enough to maintain the rule. These actions are informed by the goal to change and manage behaviour. Most initial TA training is not designed to promote conceptual or developmental change, or encourage reflective practice.

The apprenticeship model is problematic, not just for TAs, but as the Carnegie Foundation found, for all graduate students. However, as they argue, it is the signature pedagogy of graduate education, but TA work is not part of graduate education; TA work is an academic job available to graduate students while pursuing their graduate degree. 


\section{Workplace Learning}

The field of workplace learning is centered on the holistic complexity of the learning situation. A workplace learning approach takes into account the institution, mentor(s), TAs, students, and the overall context of the learning situation during the work assignment. This approach positions the working and learning role of the TA as continually changing as the TA becomes an educator in higher education.

Research in this area has looked at how and where learning is taking place in the workplace (Hager, 2011). Through this research, suggestions have been made as to how to best support and implement learning at work. An expansive/interleaved process is an example.

Expansive means providing the learner/worker with active participation in the community of practice, breadth of access to experience, paid time to engage in education, gradual transition from low risk to high risk tasks, institutional recognition that the worker is a learner, clear learning goals and personal learning plan, and more than sufficient support materials (Fuller \& Unwin, 2003).

Rather than focusing on one topic, the interleaved process involves exposure to abstract knowledge combined with exposure to situations to use the knowledge. In between the leaves of experience, is exploration of concepts related to the experience. This forefronts implicit learning and suggests that it should precede explicit or symbolic forms of learning, meaning that conceptual learning should be hung on an experiential structure rather than the other way around (Allix, 2011).

\section{Conclusion}

TAs occupy a unique position in higher education institutions: they are in a short-term work relationship, do not require any prior training or knowledge to perform the duties assigned, and assignment of a TA position provides funding as a paid job. The way in which graduate students fulfill this unique position is dependent upon the culture of the department, the duties assigned by the course supervisor, and his or her own experience and approach.

In this article, the apprenticeship model for TA preparation as currently practiced in most Canadian institutions is questioned and a workplace learning approach is put forward. The apprenticeship model currently used for graduate education is already under question and that a re-envisioning is needed (Lave and Wenger, 1991; Walker, Golde, Jones, Bueschel, \& Hutchings, 2008). Workplace learning theories, such as expansive (in opposition to restrictive) and interleaved, provide the necessary structure to enhance TA preparation. The expansive approach (Fuller \& Unwin, 2003) is simply good pedagogical practice in any situation and the interleaved approach (Allix, 2011) is appropriate for TA work because TAs are in a learning situation where they are naturally positioned to hang the conceptual on the experiential.

The addition of a workplace learning approach to TA programming was first implemented this past fall (2013). An expansive and interleaved process was embedded in the Teaching Assistant Consultant (TAC) program that positions a lead TA mentor in most departments. In the following ways, it demonstrated the effectiveness of taking a workplace learning approach to TA teaching preparation. TACs provided new TAs with access to a multitude of resources, including instruction that was sequenced and delivered to TAs as the term progressed. In addition, TACs observed TAs teaching within the first few weeks (if applicable), which included a pre-observation meeting to discuss goals of the teaching session

and a post-observation meeting to provide encouragement and feedback to the new TA. The 
TAC repeated teaching observations as required and necessary. Throughout the term, TACs were available to TAs for additional resources, one-on-one meetings, guidance at any time for consultation about TA duties, and provided additional instruction when TAs requested. The initial stages of implementing a workplace learning approach, using theories developed in this burgeoning field of study, has proven to offer TAs the support they need in order to enhance their introduction to teaching in higher education. In order to test the effectiveness of taking a workplace learning approach to TA teaching preparation, a research study will be conducted beginning in the fall of 2014 that will specifically look at the learning process TAs go through as they learn how to teach, with the aim to integrate further theories from the field of workplace learning.

\section{References}

Ainley, P. \& Rainbird H. (Eds.), (1991). Apprenticeship: Towards a New Paradigm of Learning. London: Kogan Page.

Aldrich, R. (1991). The Apprentice in History. In P. Ainley \& H. Rainbird, (Eds.), Apprenticeship: Towards a New Paradigm of Learning (pp. 15-26) London: Kogan Page.

Austin, A. E. (2002a). Creating a bridge to the future: Preparing new faculty to face changing expectations in a shifting context. The Review of Higher Education, 26(2), 119-144.

Austin, A. E. (2002b). Preparing the next generation of faculty: Graduate school as socialization to the academic career. The Journal of Higher Education, 73(1), 94-122.

Bellows, L. (2008). Graduate student professional development: Defining the field. Studies in Graduate \& Professional Student Development, 11(2), 2-19.

Boman, J. (2008). Outcomes of a Graduate Teaching Assistant Training Program (Unpublished doctoral dissertation). The University of Western Ontario, Canada.

Cho, Y., Kim, M., Svinicki, M. D. \& Lowry Deckerc, M. (2011). Exploring teaching concerns and characteristics of graduate teaching assistants. Teaching in Higher Education, 16(3), 267279.

Coy, M. W., (Ed.). (1989). Apprenticeship: from theory to method and back again. Albany, NT: State University of New York Press.

Eraut, M. (2004). Informal learning in the workplace. Studies in Continuing Education, 26(2), 247-273.

Fuller, A. \& Unwin, L. (2003). Learning as apprentices in the contemporary UK workplace: Creating and managing expansive and restrictive participation. Journal of Education and Work, 16(4), 407-426.

Garland, T. N. (1983). A training program for graduate teaching assistants: The experiences of 
one department. Teaching Sociology, 10(4), 487-503.

Hager, P. (2011). Theories of workplace learning. In M. Malloch, L. Cairns, K. Evans, \& B. N. O'Connor (Eds.), The SAGE Handbook of Workplace Learning: Theories of Work, Place and Learning: New Directions (pp. 17-29). doi:10.4135/9781446200940.

Johnson, J. \& Pratt, D. D. (1998). The apprenticeship perspective: Modeling ways of being. In D. D. Pratt (Ed.), Five Perspectives on Teaching in Adult and Higher Education, (pp. 83-101).

Jones, J. L. (1993). TA training: From the TA's point of view. Innovative Higher Education 18(2), 147-161.

Korpan, C. (2010). Report on the Impact of the Pilot Teaching Assistant Consultants (TAC) Program. Learning and Teaching Centre, University of Victoria, Canada.

Lave, J. (1988). Cognition in Practice: Mind, mathematics, and culture in everyday life. Cambridge, UK: Cambridge University.

Lave, J. \& Wenger, E. (1991). Situated Learning: Legitimate Peripheral Participation. Cambridge: Cambridge University.

Long, M. C., Holberg, J. H., \& Taylor, M. M. (1996). Beyond apprenticeship: Graduate students, professional development programs and the future(s) of English studies. WPA, 20:1/2, 66-78.

Lumsden E. A., Grosslight, J. H. Loveland, E. H. \& Williams, J. E.. (1988). Preparation of graduate students as classroom teachers and supervisors in applied and research settings. Teaching of Psychology, 15, 5-9.

Marincovich, M., Prostko, J. \& Stout, F. (1998). The Professional Development of Graduate Teaching Assistants. Bolton, MA: Anker Publishing.

Nyquist, J. D., Manning, L., Wulff, D. H., Austin, A. E., Sprague, J., Fraser, P. K., Calcagno, C. \& Woodford, B. (1999). On the road to becoming a professor: The graduate student experience. Change, 31(3), 18-27.

Schonwetter, D. J., Ellis, D.E., Nazarko, O. \& Taylor, K. L. (2004). North of the 49th parallel: diverse (Canadian) approaches to graduate student professional development programs for teaching. Paper from: Professional and Organizational Development Network in Higher Education. Montreal, Quebec, Canada.

Shulman, L. S. (2005). Signature pedagogies in the professions. Daedalus, 52-59.

Sullivan, W. M. (2005). Work and Integrity: The Crisis and Promise of Professionalism in America, ( ${ }^{\text {nd }}$ Ed.). San Francisco, CA: Jossey-Bass.

Walker, G. E., Golde, C. M., Jones, L., Conklin Bueschel, A. \& Hutchings, P. (2008). The 
Formation of Scholars: Rethinking Doctoral Education for the Twenty-First Century. The Carnegie Foundation for the Advancement of Teaching. San Francisco, CA; Jossey-Bass.

Weber, R. J., Gabbert, A., Kropp, J. \& Pynes, P. (2007). Creating the teaching professor: Guiding graduate students to become effective teachers. The Journal of Scholarship of Teaching and Learning, 7(1), 45-63.

Wenger, E. (1998). Communities of practice: learning, meaning, and identity. Cambridge: Cambridge University. 